\title{
Effects of Astaxanthin from Litopenaeus Vannamei on Carrageenan-Induced Edema and Pain Behavior in Mice
}

\author{
Zulkiflee Kuedo ${ }^{1}$, Anantita Sangsuriyawong ${ }^{2}$, Wanwimol Klaypradit ${ }^{2}$, Varomyalin Tipmanee ${ }^{3}$ \\ and Pennapa Chonpathompikunlert ${ }^{1, *}$ \\ 1 Department of Physiology, Faculty of Science, Prince of Songkla University, \\ Hat Yai, Songkhla 90112, Thailand; lee.kuedo@gmail.com \\ 2 Center for Advanced Studies for Agriculture and Food, Kasetsart University, Bangkok 10900, Thailand; \\ anantita_sw@hotmail.com (A.S.); ffiswak@ku.ac.th (W.K.) \\ 3 Department of Biomedical Sciences, Faculty of Medicine, Prince of Songkla University, \\ Hat Yai, Songkhla 90110, Thailand; tvaromya@medicine.psu.ac.th \\ * Correspondence: pennapa.ch@psu.ac.th; Tel.: +66-7428-8215
}

Academic Editors: Anake Kijjoa, Bungorn Sripanidkulchai and Maria Emilia de Sousa Received: 18 February 2016; Accepted: 16 March 2016; Published: 19 March 2016

\begin{abstract}
Carrageenan produces both inflammation and pain when injected in mouse paws via enhancement of reactive oxygen species formation. We have investigated an effect of astaxanthin extracted from Litopenaeus vannamei in carrageenan-induced mice paw edema and pain. The current study demonstrates interesting effects from astaxanthin treatment in mice: an inhibition of paw edema induced in hind paw, an increase in mechanical paw withdrawal threshold and thermal paw withdrawal latency, and a reduction in the amount of myeloperoxidase enzyme and lipid peroxidation products in the paw. Furthermore the effect was comparable to indomethacin, a standard treatment for inflammation symptoms. Due to adverse effects of indomethacin on cardiovascular and gastrointestinal systems, our study suggests promising prospect of astaxanthin extract as an anti-inflammatory alternative against carrageenan-induced paw edema and pain behavior.
\end{abstract}

Keywords: astaxanthin; Litopenaeus vannamei; inflammatory pain; carrageenan; myeloperoxidase; mice

\section{Introduction}

Inflammation is a cellular response to a traumatic injury, irritation from toxic chemicals, or infection caused by microbial pathogens. This complex process involves numerous pathways of cellular and plasma origin with interrelated biological events, often leading to painful conditions, such as in rheumatoid arthritis, asthma, allergy, inflammatory bowel syndrome, atherosclerosis, and neurodegenerative disease [1,2]. The phenomena of inflammations are largely regulated by various mediators like reactive oxygen and nitrogen intermediates, prostacyclins, prostaglandin, leukotrienes, cytokines, and histamine, which could be expressed in macrophages, hepatocytes, and endothelial or smooth muscle cells [3]. One of distinctive mediators is nitric oxide radical, generated from the terminal guanido-nitrogen atom of L-arginine by NADPH-dependent enzymes known as nitric oxide synthase (NOS), of which the $\mathrm{Ca}^{2+}$ independent inducible form (iNOS) has been expressed in inflamed tissues in response to lipopolysaccharide (LPS), interferon-gamma (INF- $\gamma$ ), tumor necrosis factor (TNF), interleukin-1beta (IL-1 $\beta$ ), and found to be responsible for the pathophysiology of inflammation [4]. The highly reactive nitric oxide radical could be initiated form another stronger oxidant, viz. peroxynitrite $\left(\mathrm{ONOO}^{-}\right)$by combining with superoxide anion radicals, harmful to functional normal tissues [5,6]. This aforementioned statement reflects the role of reactive oxygen and nitrogen species in the pathophysiology of inflammation. In addition scavenging of superoxide 
radicals and suppression of nitric oxide and iNOS protein could represent a novel therapeutic approach against inflammatory diseases.

In general, steroids and cyclooxygenase inhibitors such as prednisolone, aspirin, and indomethacin have long been used as the main therapeutic anti-inflammatory agents, but they are frequently associated with significant detrimental effects in patients especially gastrointestinal toxicity $[7,8]$. Non-steroidal anti-inflammatory drugs (NSAIDs) clearly promote reactive oxygen species (ROS) production. It was proposed that NSAID-mediated gastrointestinal lesions involve the uncoupling of oxidative phosphorylation and inhibition of the electron transport chain causing incomplete reduction of oxygen. Indomethacin, a potent NSAID, was found to bind to a site near complex I and ubiquinone to generate ROS $[9,10]$, and ROS can damage cellular lipids, proteins, and DNA, leading to oxidative stress [11]. Potentially developing natural alternative anti-inflammatory supplements have, thus, increasingly become important [12]. This approach seemingly overcomes the incidences of drug related toxicity and iatrogenic reactions caused by $90 \%$ of the non-steroidal anti-inflammatory drugs (NSAIDs) commonly used for treatment of inflammatory conditions [13]. Hence, it would be interesting to explore some of the exotic dietary ingredients customary in ethnic cultures around the world so that the natural product with prospective anti-inflammatory properties could be well-documented and validated scientifically.

Many phytochemicals, particularly carotenoids and flavonoids, are well-known of capability in cellular redox imbalance modulation, as well as the endothelial and metabolic processes regarding the pathogenesis of inflammatory. Astaxanthin is one of the most common carotenoids and found in the red pigment in crustacean shells (crabs, shrimps, for example), salmon, and Asteroidean [14]. Moreover, astaxanthin, as a nutraceutical, has been reported to possess the potential preventive capacity associated with health benefits [15] partly due to its free radical antioxidant activity up to 100-fold stronger than vitamin E [16]. Additionally, previous studies demonstrated that astaxanthin intake as a nutritional supplement can prevent oxidative damages resulting in a decrease in some chronic diseases [17-19], exhibit anti-tumor activity [20], inhibit proliferation of breast and colon cancer [21,22], and reduce significantly chronic inflammatory diseases [23-25]. Since the common source, like Haematococcus pluvialis, is not able to be cultivated in Thailand, an interesting alternative source of astaxanthin is Litopenaeus vannamei, which plays an enormous role in national exportation. Large amount of crustacean shells are however wastefully left out. Additionally, any scientific supports for astaxanthin from have not yet been established. Herein the present study reported the anti-inflammatory activities of astaxanthin extracted from the white shrimp shell (Litopenaeus vannamei) mostly found in Thailand.

\section{Results}

\subsection{Effects of Astaxanthin on Carrageenan-Induced Paw Edema}

As shown in Figure 1, indomethacin $(5 \mathrm{mg} / \mathrm{kg})$, a standard anti-inflammatory drug, and astaxanthin at a dose of 100-150 $\mathrm{mg} / \mathrm{kg}$ significantly suppress the carrageenan-induced increases in paw thickness $(3.81 \pm 0.08,3.76 \pm 0.19,3.75 \pm 0.29 \mathrm{~mm}$ at $2 \mathrm{~h}$ and $4.01 \pm 0.19,3.93 \pm 0.30$, $3.79 \pm 0.13 \mathrm{~mm}$ at $6 \mathrm{~h}$, respectively) compared to propylene glycol-treated animals (vehicle controls) $(4.22 \pm 0.15 \mathrm{~mm})$ at $2 \mathrm{~h}$ and $(4.65 \pm 0.21 \mathrm{~mm})$ at $6 \mathrm{~h}$ after the injection. Although a significant increase in paw thickness was observed in all groups, the mice that received indomethacin or astaxanthin displayed significantly less edema. Furthermore, astaxanthin (100-150 mg/kg) displayed a similar efficacy to indomethacin in the suppression of inflammation-induced increase in paw thickness. However, a low dose of astaxanthin $(50 \mathrm{mg} / \mathrm{kg}$ ) showed no significant effect (Figure 1). The ineffectiveness of this low dose may be due to its insufficient therapeutic dose to express the protective effect for an inflammation. 


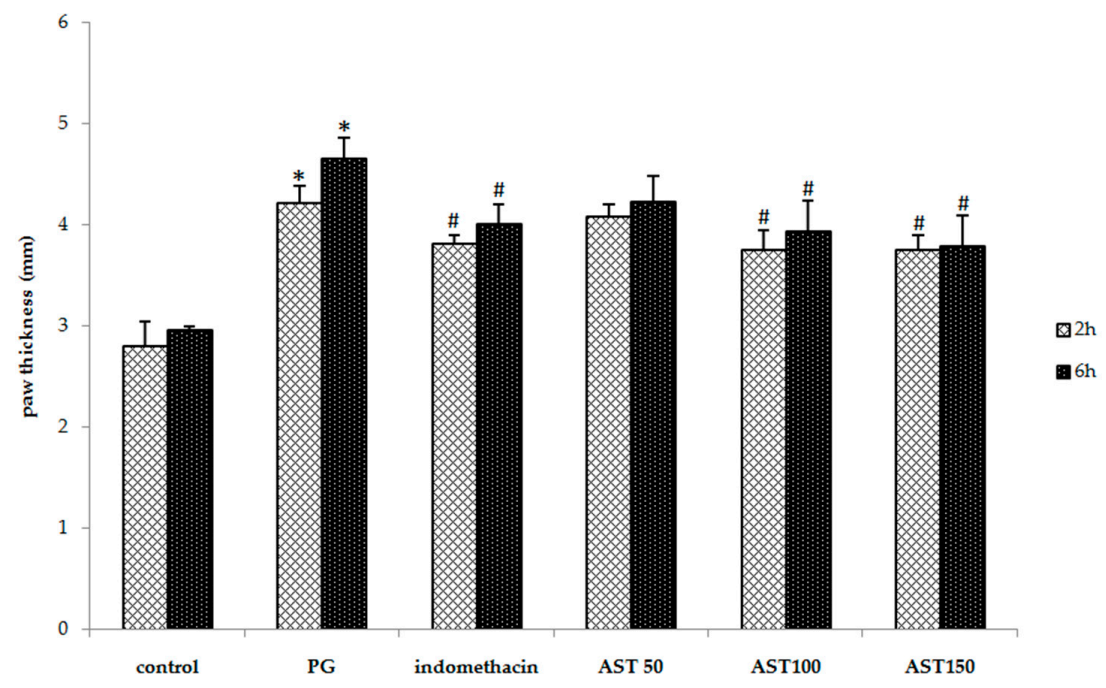

Figure 1. Effect of astaxanthin (AST) on carrageenan-induced paw edema (mm). Data are presented as mean $\pm \mathrm{SD}$. * vs. naïve control, $p<0.05$ with respect to identical time; \# vs. vehicle control (propylene glycol or PG), $p<0.05$ with respect to identical time; $n=8$ mice/group.

\subsection{Effects of Astaxanthin on Carrageenan-Induced Hyperalgesia}

Each mouse received propylene glycol, astaxanthin $(100-150 \mathrm{mg} / \mathrm{kg})$ or indomethacin $(5 \mathrm{mg} / \mathrm{kg})$ via oral gavage, directly followed by a hind paw injection of $2.5 \%$ carrageenan $(50 \mu \mathrm{L})$. A one-way ANOVA revealed that the carrageenan-induced thermal and mechanical threshold was significantly suppressed by indomethacin and astaxanthin $(P<0.05)$. Post hoc statistical testing showed that the paw withdrawal latency and mechanical paw withdrawal threshold of animals treated with astaxanthin or indomethacin were significantly greater than which of vehicle-treated mice at 2 and $6 \mathrm{~h}$ after the carrageenan injection (Figures 2 and 3). In addition, no significant difference between the astaxanthin (100-150 mg/kg) and indomethacin-treated animals was observed. These results indicate that astaxanthin was as effective as indomethacin in reducing inflammation-induced thermal and mechanical hyperalgesia. Note that a dose of $50 \mathrm{mg} / \mathrm{kg}$ was not effective to decrease hyperalgesia.

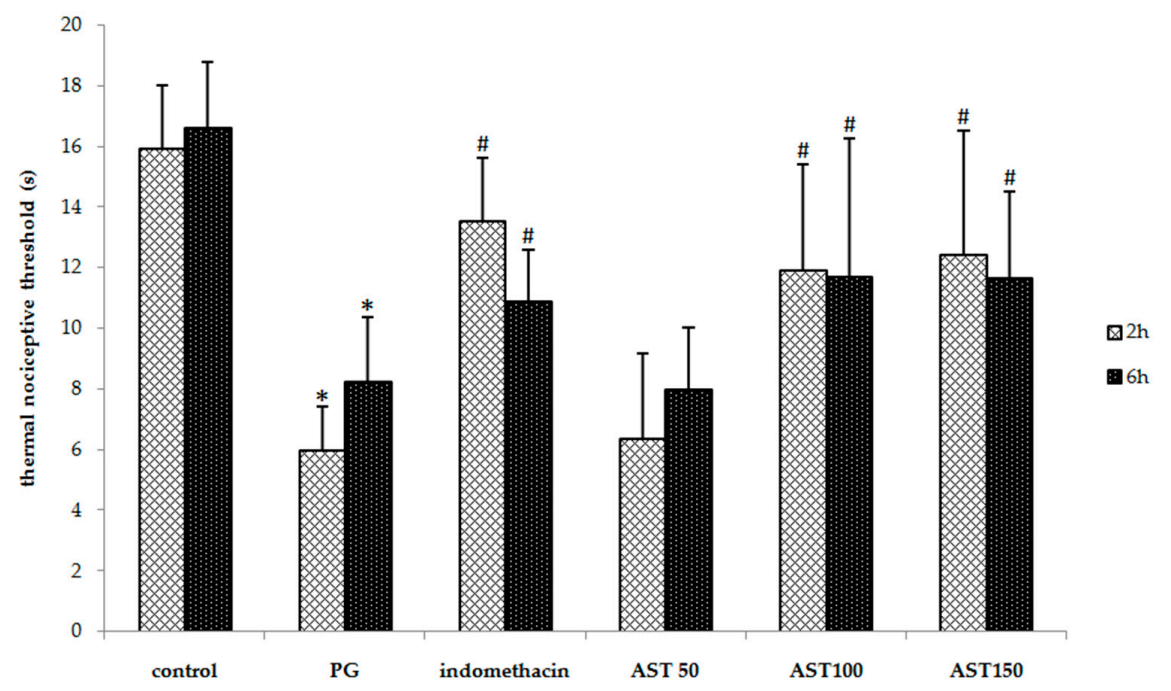

Figure 2. Effect of astaxanthin (AST) on carrageenan-induced thermal hyperalgesia. Data are presented as mean $\pm \mathrm{SD}$. * $v$ s. naïve control, $p<0.05$ with respect to identical time; \# vs. vehicle control (propylene glycol or PG), $p<0.05$ with respect to identical time; $n=8$ mice/group. 


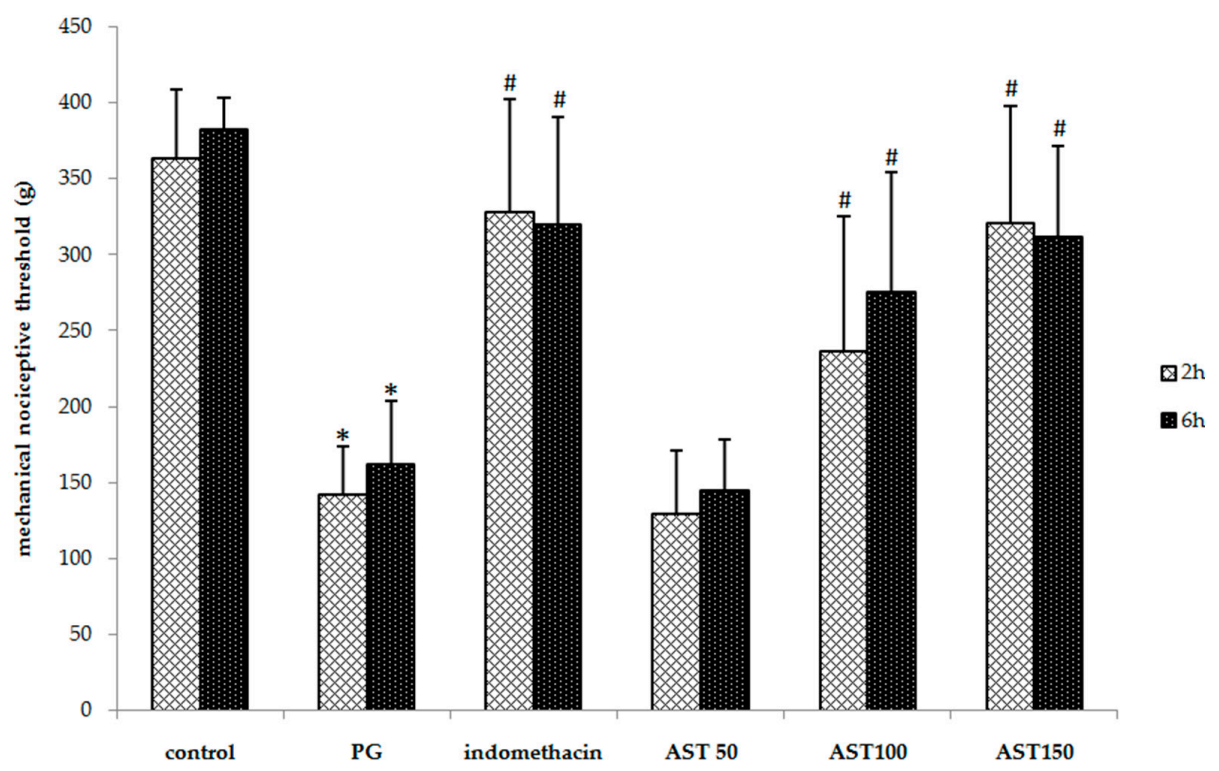

Figure 3. Effect of astaxanthin (AST) on carrageenan-induced mechanical hyperalgesia. Data are presented as mean $\pm \mathrm{SD}$. ${ }^{*}$ vs. naïve control, $p<0.05$ with respect to identical time; \# vs. vehicle control (propylene glycol or PG), $p<0.05$ with respect to identical time; $n=8 \mathrm{mice} /$ group.

\subsection{Effects of Astaxanthin on Carrageenan-Induced MPO Accumulation}

Indomethacin and astaxanthin (100-150 mg/kg) significantly reduced the neutrophil content, evaluated from myeloperoxidase activity, in the carrageenan-induced inflammation. The myeloperoxidase concentration (i.e., the neutrophil recruitment) in the hind paw of indomethacin, astaxanthin $100 \mathrm{mg} / \mathrm{kg}$ and astaxanthin $150 \mathrm{mg} / \mathrm{kg}$ treated mice were $0.558 \pm 0.154,0.478 \pm 0.106$, and $0.429 \pm 0.063$ units $/ \mathrm{mg}$ protein respectively, compared to $0.722 \pm 0.195$ units $/ \mathrm{mg}$ protein in the vehicle controls $(p<0.05)$ (Figure 4 ), whereas $50 \mathrm{mg} / \mathrm{kg}$ had given an unsatisfying result $(0.645 \pm 0.166$ units $/ \mathrm{mg}$ protein).

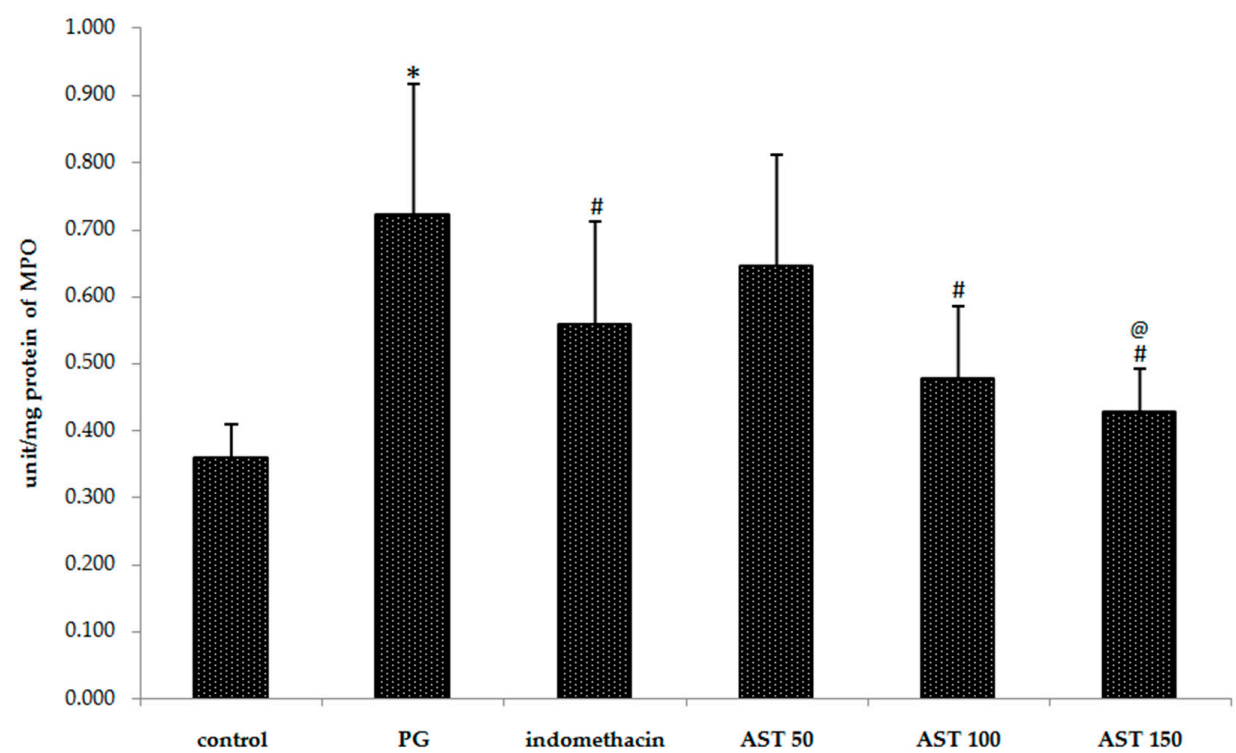

Figure 4. Effect of astaxanthin (AST) on carrageenan-induced MPO accumulation. Data are presented as mean $\pm \mathrm{SD} .{ }^{*}$ vs. naïve control, $p<0.05$; \# vs. vehicle control (propylene glycol or PG), $p<0.05$; @ vs. indomethacin, $p<0.05 ; n=8$ mice/group. 


\subsection{Effects of Astaxanthin on Carrageenan-Induced ROS Release}

In order to evaluate free radical level, inhibition percentage of superoxide anion and malondialdehyde (MDA) level were measured. We found that carrageenan-treated groups show significantly increased superoxide anion level and MDA level in paw tissue. Indomethacin and astaxanthin (100-150 mg/ $\mathrm{kg}$ ) treated group showed significant effect to attenuate superoxide anion and MDA increase after carrageenan injection in paw tissue (Figures 5 and 6). A low dose $(50 \mathrm{mg} / \mathrm{kg}$ ) displayed an insignificantly different effect compared to PG group.

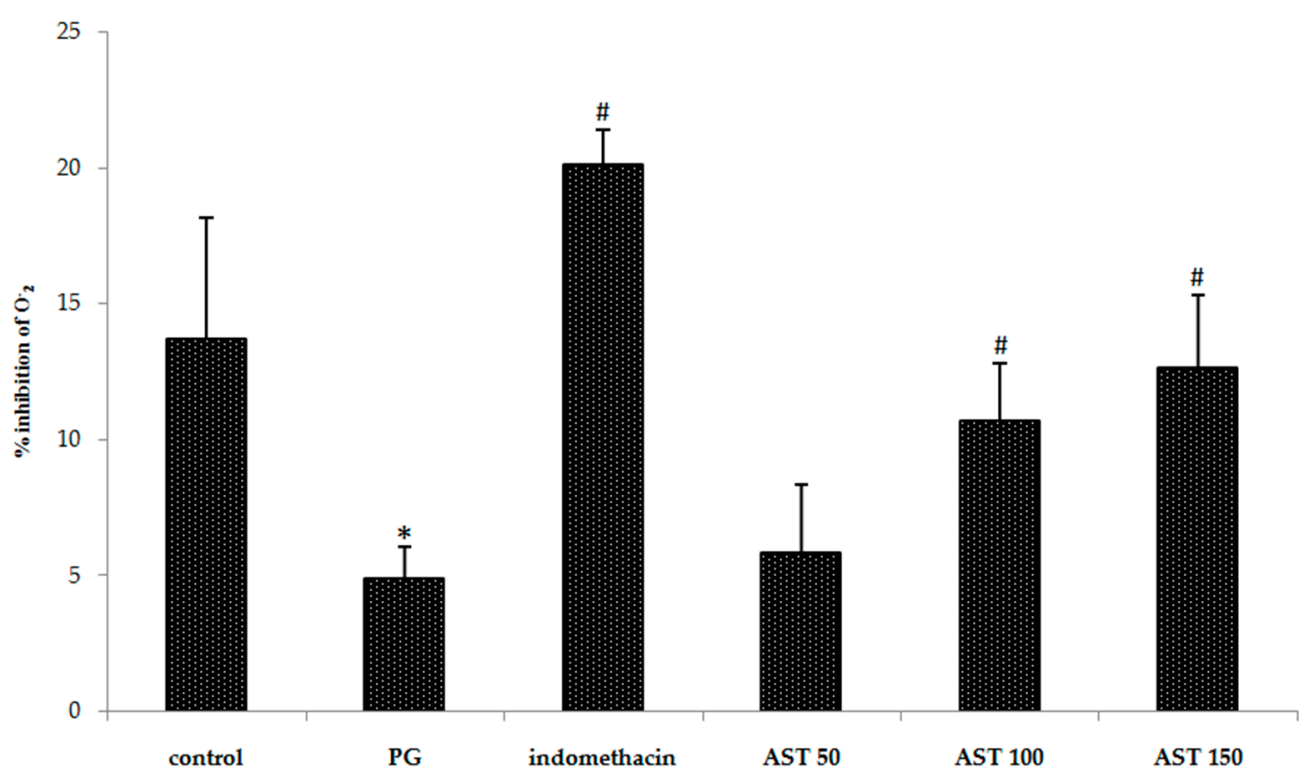

Figure 5. Effect of astaxanthin (AST) on carrageenan-induced ROS release. Data are presented as mean $\pm \mathrm{SD}$. * vs. naïve control, $p<0.05$; \# vs. vehicle control (propylene glycol or PG); $n=8$ mice/group.

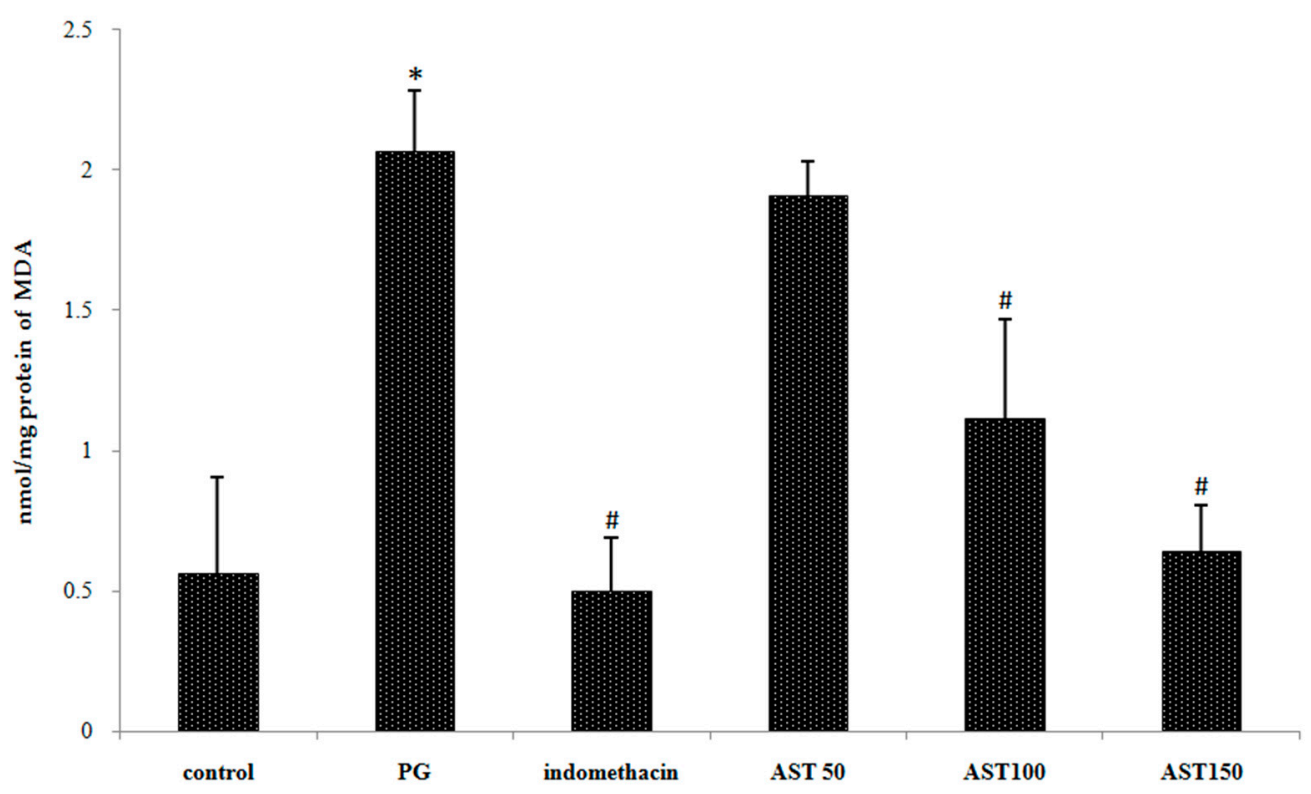

Figure 6. Effect of astaxanthin (AST) on carrageenan-induced lipid peroxidation product or MDA. Data are presented as mean \pm SD. * $v$ s. naïve control, $p<0.05$; \# vs. vehicle control (propylene glycol or PG); $n=5$ mice/group. 


\section{Discussion}

The most common test to screen new anti-inflammatory agents in order to elucidate the ability of a compound to reduce local edema induced is to inject an irritant agent into the rodent paw [26]. Carrageenan-induced edema has been widely used as an experimental animal model for acute inflammation and is believed to be biphasic. An initial phase lasting up to $2 \mathrm{~h}$ is primarily mediated via rapid production of inflammatory mediators such as histamine, serotonin, bradykinins, and increased synthesis of prostaglandins in the damaged tissue surroundings [27-30]. In contrast, the late phase lasting from 3-6 h is sustained by prostaglandin release from macrophages and mediated by bradykinin, leukotrienes, polymorphonuclear cells, mobilized phagocytic cells, monocytes, macrophages, ROS, nitric oxide, proteolytic enzymes, and platelet activating factor [27,29-33]. The present study showed that astaxanthin extract, via oral administration, simultaneously inhibited both phases in the carrageenan-induced paw edema test (Figure 1). These reports supported that the time period for induced inflammatory response of carrageenan displayed different severity which is consistent with previous studies [34,35].

Increased pain sensitivity is a common feature of the inflammatory response and occurs after tissue injury. The peripheral sensitization is triggered by NF- $k$ B-related pro-inflammatory mediators, including the cytokines TNF- $\alpha$ and IL-1 $\beta$ [36-38], as well as ROS, such as the superoxide anion radical [39]. In addition to their role in the inflammatory response, these mediators can act directly on their receptors or targets expressed by peripheral terminals of nociceptors to reduce pain thresholds, leading to inflammatory pain and hyperalgesia [40,41]. Moreover, an induction of neutrophils recruitment leads to the further enhancement of hyperalgesic mediators, such as prostaglandin $E_{2}$ $\left(\mathrm{PGE}_{2}\right)$ and the superoxide anion [36,39]. Previous studies also reported that carrageenan is a known toxic substance to induce hyperalgesia in rodents $[42,43]$. These reports were corresponding to a mode of action shown in our data that carrageenan can decrease paw withdrawal latency and mechanical paw withdrawal threshold when compare to the vehicle control group. Interestingly, astaxanthin extract at a dose of 100-150 mg/kg via the oral route can attenuate and decreased both thermal and mechanical nociceptive threshold tests (Figures 2 and 3). This emphasizes that our astaxanthin extract therefore diminished the carrageenan-induced hyperalgesia. Moreover, previous study found that astaxanthin can inhibit ROS-induced production of NF- $\mathrm{kB}$ transcription factor, which in turn effectively inhibits the production of inflammatory cytokines [44]. So, astaxanthin extract may decrease pain via inhibiting the pro-inflammatory cytokine mediator.

Since neutrophil recruitment is an important mediator of inflammation, and the enzyme MPO is a reliable marker for the detection of neutrophil accumulation in inflamed skin in vivo [45], we have measured the MPO activity in the mouse paw injected with carrageenan. The results show that astaxanthin extract could decrease its activity (Figure 4). Hence, it will be reasonable to speculate that an inhibition of MPO occurred through the neutrophil modulation, which could partially account, at least, for the anti-inflammatory properties of astaxanthin.

Oxidants are well-known in playing a significant role in the pathogenesis of a number of disorders such as inflammation. Oxidative stress is defined as an imbalance between cellular production of ROS and antioxidant defense mechanisms. ROS (e.g., superoxide radical, peroxynitryl, hydroxyl radical, and hydrogen peroxide) are key signaling molecules in the progression of inflammatory disorders. An enhanced ROS generation by polymorphonuclear neutrophils (PMNs) at the site of inflammation causes endothelial dysfunction and tissue injury $[46,47]$. However, superoxide anion level cannot be directly measured. To evaluate the level, the measurement of superoxide anion inhibition was instead applied. In our experiment, carrageenan-induced model can successfully produce ROS (Figure 5 PG group), similar to previously reported experiments [48]. Herein MDA was chosen as a biomarker to confirm ROS occurrence because ROS can damage cellular tissue, and plasma membrane, leading to a product due to lipid peroxidation called MDA $[49,50]$. Thus, inflammatory response would cause the accumulation of MDA. Interestingly our results indicated that the MDA production was reduced by treatment of astaxanthin extract (Figure 6). The results likely provide information regarding 
anti-inflammatory property of astaxanthin extract which is in accordance with the published study concerning astaxanthin as a free radical scavenger via singlet oxygen quenching [51]. Apart from MDA production, we also evaluate an anti-inflammatory property of astaxanthin by a comparison to a case study of superoxide dismutase (SOD) enzyme. Typically, SOD is a scavenging enzyme responsible for free radical regulation. The use of poly(ethylene glycol)-linked human recombinant SOD suggested that the generation of superoxide anions, together with nitric oxide, and peroxynitrite, involves in the acute carrageenan-induced paw edema [33,52]. Early clues of evidence pointed for the implication of superoxide anion in acute carrageenan-induced inflammation [53], as well as in ischemic paw edema [54]. A study of SOD mimetic M40403, implicated a key role for superoxide anion in inflammatory pain [39]. In this study, it is noteworthy that astaxanthin extract from Litopenaeus vannamei (100-150 mg/kg), where all experiments were performed using carrageenan-induced inflammation, display inhibitory effects against superoxide anion radical (Figure 5) similar to the earlier result [55]. Our study was adequate to imply active SOD-like potency.

As we have known that indomethacin can act as an inhibitor of prostaglandin production via inhibition of cyclooxygenase 1 and 2 enzymes in the late phase of carrageenan-induced inflammation [56,57], our results show that astaxanthin extract exhibit an efficacy (100-150 mg/ kg) comparable to indomethacin $(5 \mathrm{mg} / \mathrm{kg})$ in all experiments including edema, thermal and mechanical hyperalgesia, inhibition percentage of superoxide anion, MDA level, and MPO activity. However, the therapeutic effect of indomethacin is stronger, if one considered at the same dose. Although indomethacin demonstrated efficacy in pain relief and inflammation [58], indomethacin is found to be associated with a lot of numbers of adverse effects, for example, alterations in renal function, effects on blood pressure, hepatic injury and platelet inhibition which may result in increased bleeding. In addition, the most important adverse effects of indomethacin are the gastrointestinal and cardiovascular adverse effects, respectively [59]. This leaves an opportunity for astaxanthin extract to be an interesting choice for pain control from inhibits inflammation process.

Previous studies reported that an astaxanthin extract from Aristeus alcocki (Arabian red shrimp) shell waste is a more powerful antioxidant than one in the Haematococcus pluvialis [60]. A higher proportion of astaxanthin diester and a higher content of poly unsaturated fatty acids $(20 \%$ PUFAs in monoester and 30\% PUFAs in diester) in the carotenoid extract obtained from Aristeus alcocki shell is suggested to be responsible for the distinctive antioxidant property. Significant evidence supports the versatile properties of astaxanthin as a neutraceutical, such as protective effect from oxidative stress in healthy smokers [17], tumor prevention in breast cancer [21], oral cancer [61] and colon cancer [22], and cardiovascular disease [62], as well as neurodegenerative disease and metabolic syndromes [63]. Interestingly, our astaxanthin extract from Litopenaeus vannamei (Pacific white shrimp) shell waste contains PUFA content of $61.74 \%$ [64], leading to an implication that the powerful antioxidant property of carotenoid extract of Litopenaeus vannamei may be attributed to the antioxidant synergism of astaxanthin and PUFAs present in the extract. Moreover, free astaxanthin that accounted from Litopenaeus vannamei also showed a large percentage (32.95\%), different from the pattern of Haematococcus pluvialis (5\%) [65]. Although the effect of astaxanthin from Aristeus alcocki (Arabian red shrimp) shell waste can inhibit carrageenan-induced inflammation in mice [60], the source of astaxanthin extract and route of administration are different from our study. To sum up, our study offers a new source of astaxanthin with a better potency to protect inflammation.

\section{Materials and Methods}

\subsection{Animals}

Male ICR mice, eight weeks old, weighting 30-35 g, were acclimated to housing for at least one week prior to investigation. Mice were on a 12/12-h day/night cycle, a relative humidity of $50 \%$, with food and water provided ad libitum. All administrations in this study were performed once daily between 8:00-9:00 a.m. Six groups of ICR mice $(n=8)$ were randomly assigned into naïve control, 
vehicle control (propylene glycol treated groups), positive control (indomethacin treated groups), and treatment groups $(50,100,150 \mathrm{mg} / \mathrm{kg}$ of astaxanthin). Experimental procedures have been performed in accordance with the principles of animal care outlined by Faculty of Science, Prince of Songkla University (Ethic No. MOE 0521.11/019). The studies were performed according to the guidelines of the Committee for Research and Ethical Issues of the International Association for the Study of Pain [66].

\subsection{Model of Inflammation}

In this model, each mouse was injected with $50 \mu \mathrm{L}$ of the inflammatory agent under brief isoflurane anesthesia (3\%). To assess the effects of astaxanthin from the white shrimp shell on paw edema, 2.5\% carrageenan suspension ( $w / v$ with $0.9 \%$ saline) was injected into both hind paws.

\subsection{Extraction of Astaxanthin from White Shrimp Shell}

Fresh white shrimp (Litopenaeus vannamei) shells were obtained from a frozen shrimp processing plant in Samut-Sakorn province, Thailand. The samples were packed and stored frozen at $-20{ }^{\circ} \mathrm{C}$. Prior to use, samples were thawed by submerging samples under cool running tap water. Astaxanthin extraction was prepared according to the procedure described by Sachindra, Bhaskar, and Mahendrakar [67] with slight modification in that food-grade ethanol was used as a solvent. Shrimp shell was blended with ethanol in the ratio of 1:2 (shrimp shell:ethanol) using a Waring laboratory blender (Waring Laboratory Science, Winsted, MN, USA). Shrimp shell residues were vacuum filtered. The collected extract was then evaporated under vacuum at $40^{\circ} \mathrm{C}, 175 \mathrm{MPa}$ using a Büchi R-124 rotary evaporator (Büchi Labortechnik AG, Flawil, Switzerland) to obtain astaxanthin. Herein, extraction yield was $20.39 \pm 1.02 \mathrm{mg}$ of astaxanthin/g shrimp shell.

\subsection{Measurement of Paw Edema}

Paw thickness was used as a measurement of inflammation-induced edema [26-31]. Briefly, the dorsoventral thickness of each hind paw was measured using a caliper placed at the border of the phalanges and the metatarsals. The measurement was taken when each edge of the caliper was just touching the dorsal and ventral surface of the hind paw (i.e., the caliper was not squeezed onto the hind paw). Data are expressed as the mean paw thickness \pm SD.

\subsection{Behavioral Assessment of Thermal Nociceptive Threshold Test}

Animals were acclimated to the laboratory environment, investigator handling and behavioral equipment during at least two training sessions. A single investigator injected all animals and collected all behavioral data. To blind the investigator during the behavioral measurements, multiple substances doses were used in each experimental session and the animals were randomly placed onto the testing apparatus. The room temperature of the behavioral testing facility was maintained at $3 \pm 2{ }^{\circ} \mathrm{C}$.

The unilateral hot plate test (the plantar side of one hind paw is placed on a hot plate surface and, thus, the withdrawal latency of each paw can be measured separately) was employed to measure central analgesic activity by the method of Menèndez et al., with modifications from Hargreaves et al. [68,69]. Thermal paw withdrawal latencies (PWL) to radiant heat stimuli were recorded from the left and right hind paw of each mouse. Mice were placed into plexiglass chambers on a glass surface that was heated to $45 \pm 1^{\circ} \mathrm{C}$. Following a $10 \mathrm{~min}$ acclimation period, a radiant heat stimulus was alternately applied to each hind paw, and the time to paw withdrawal measured. Each hind paw was tested two times. A 20 s exposure limit was imposed to prevent tissue damage, and a 5 min interval was maintained between trials to avoid sensitization. The PWL was calculated as the mean of two trials from both paws, and data across animals are presented as the mean \pm S.D. 


\subsection{Behavioral Assessment of Mechanical Nociceptive Threshold Test}

The mechanical nociceptive withdrawal threshold was assessed by using the Randall-Selitto electronic algesimeter (Ugo basile, Analgesy-Meter Cat. No. 37215, Italy). Before the test, each animal received 5 min of handling to get used to manipulation. The tested paw will be placed between a flat surface and wedge-shaped blunt piston, an increasing mechanical force will be applied via a piston onto the dorsal surface of the paw. When the mouse experiences pressure on the paw, it makes reflex movement of withdrawal. Immediately, the application of pressure will be stopped and the threshold (weight in grams) is recorded. The maximum force applied was limited to $200 \mathrm{~g}$ to avoid any tissue damage [70].

\subsection{Myeloperoxidase (MPO) Assay}

To determine the recruitment of neutrophils in response to the carrageenan induced inflammation in the mouse hind paw, the paws were weighed and homogenized in cold $50 \mathrm{mM}$ phosphate buffer pH 6 involved 0.5\% hexadecyltrimethyl-ammonium bromide (Sigma Chemical Co., St. Louis, MO, USA). Supernatants were collected by centrifugation for $10 \mathrm{~min}$ at $10,000 \mathrm{rpm}$ at $4{ }^{\circ} \mathrm{C}$ and kept at $-80{ }^{\circ} \mathrm{C}$ and freeze-thawed, whereafter the myeloperoxidase activity of the supernatant was assessed. The enzyme reaction was carried out in a 96-well plate by adding $190 \mu \mathrm{L}$ of $50 \mathrm{mM}$ phosphate buffer pH 6, $5 \mu \mathrm{L}$ of $0.5 \%$ o-dianisidine hydrochloride, $5 \mu \mathrm{L}$ of $20 \mathrm{mM} \mathrm{H}_{2} \mathrm{O}_{2}$ and $10 \mu \mathrm{L}$ of supernatant sample. After keeping reaction for $30 \mathrm{~min}$ at room temperature, the absorbance at $460 \mathrm{~nm}$ was measured using a microplate reader (ASYS UVM 340, Biochrom Ltd., Cambridge, UK). MPO activity was determined by using the curve from the standard MPO (Sigma Chemical Co.). Values are expressed as MPO units/mg protein.

\subsection{Superoxide Anion Assay}

Superoxide anions are particularly important as the product of the one-electron reduction of dioxygen superoxide anions, which are widely produced in large quantities by the enzyme NADPH oxidase for use in oxygen-dependent killing mechanisms of invading pathogens but superoxide is biologically toxic. The superoxide anion level was determined by spectrophotometric measurement using a microplate reader (ASYS UVM 340, Biochrom Ltd.). The method based on xanthine/xanthine oxidase (XO) system which converted nitro blue tetrazolium (NBT)-yellow color to formazan-blue color. The reagent mix was prepared of $0.3 \mathrm{mM}$ EDTA, $0.6 \mathrm{mM} \mathrm{NBT}, 0.1 \mathrm{mM}$ xanthine and $0.02 \mathrm{U} / \mathrm{mL} \mathrm{XO}$, mixed with sample and measured at $560 \mathrm{~nm}$ compared with standard curve of 4-hydroxy-2,2,6,6-tetramethylpiperidin-1-oxyl (TEMPOL). The data were expressed as \% inhibition which was calculated following the equation [71].

$$
\% \text { inhibition }=(\mathrm{A}-\mathrm{B}) / \mathrm{A} \times 100
$$

$\mathrm{A}=\mathrm{OD}$ of reagent only; $\mathrm{B}=\mathrm{OD}$ of sample.

\subsection{Measurement of Lipid Peroxidation}

Lipid peroxidation was evaluated by measuring the amount of MDA, following the method of Uchiyama and Mihara [72]. Samples of intestinal tissue from treated mice were collected, homogenized in cold $0.1 \mathrm{mM}$ phosphate buffer ( $\mathrm{pH} 7.4$ ), and centrifuged at $10,000 \mathrm{rpm}$ at $4{ }^{\circ} \mathrm{C}$ for $15 \mathrm{~min}$. An aliquot of the supernatant was added to the reaction mixture containing $8 \%(w / v)$ sodium dodecyl sulfate, $20 \%(v / v)$ acetic acid, $0.8 \%(w / v)$ thiobarbituric acid, and distilled water. After incubation at $95{ }^{\circ} \mathrm{C}$ for $1 \mathrm{~h}$, the amount of MDA formed in the reaction mixture was measured using a microplate reader (ASYS UVM 340, Biochrom Ltd.) at an absorbance of $532 \mathrm{~nm}$. 1,1,3,3-tetramethoxypropane was used as the standard. The protein concentration of the supernatant sample was measured using the BCA kit as well as the MPO assay. 


\subsection{Experimental Design}

Astaxanthin were delivered as a solution with propylene glycol. Indomethacin (Wako Pure Chemical Industries, Ltd., Saitama, Japan), a potent non-steroidal anti-inflammatory agent, was suspended in a propylene glycol. Indomethacin $(5 \mathrm{mg} / \mathrm{kg})$ has been reported to reduce pain and inflammation associated with acute inflammation $[73,74]$ and serves as a positive control in this study. Propylene glycol was used as a vehicle control.

Mice were randomly separated to each treatment group ( $n=8$ mice per group). Mice received astaxanthin at various doses ranging from $50-100 \mathrm{mg} / \mathrm{kg}$ once daily for three weeks and received indomethacin at a daily dose of $5 \mathrm{mg} / \mathrm{kg}$ for one week before carrageenan-induced paw edema. At the last dose of oral administration with astaxanthin (50-100 mg/kg), indomethacin (5 mg/ kg), or propylene glycol, each animal received the intraplantar injection of $2.5 \%$ carrageenan $(50 \mu \mathrm{L})$ from Wako Pure Chemical Industries, Ltd. Saitama, Japan. The paw edema testing was performed 2 and $6 \mathrm{~h}$ after the carrageenan injection.

\subsection{Statistical Analyses}

All data were presented as the means \pm SD. Differences between the mean values for individual groups were assessed by a one-way analysis of variance (ANOVA), followed by LSD's post hoc test. $p<0.05$ was considered to indicate a statistically significant difference. The SPSS version 13 (IBM Corp., Armonk, NY, USA) was used for the analysis.

\section{Conclusions}

Astaxanthin extract from Litopenaeus vannamei have well suppressed nociceptive behaviors associated with acute inflammation and provided a beneficial role in the treatment of inflammatory pain. Also, the results support that astaxanthin can be applied for anti-inflammatory conditions. However, further research is necessary to improve the efficacy and stability of astaxanthin extract, as well as more clinical investigations are required to substantiate this report.

Acknowledgments: This project received financial support from Graduate School of Prince of Songkla University and Center for Advanced Studies for Agriculture and Food of Kasetsart University, General project and invention of Prince of Songkla University, Thailand.

Author Contributions: P.C. and W.K. conceived and designed the experiments; Z.K. and A.S. performed the experiments; Z.K. and P.C. analyzed the data; P.C. and W.K. contributed reagents/materials/analysis tools; P.C. and V.T. wrote the paper. All authors read and approved the final manuscript.

Conflicts of Interest: The authors declare no conflict of interest.

\section{References}

1. Iwalewa, E.O.; McGraw, L.J.; Naidoo, V.; Eloff, J.N. Inflammation: The foundation of diseases and disorders. A review of phytomedicines of South African origin used to treat pain and inflammatory conditions. Afr. J. Biotechnol. 2007, 6, 2868-2885.

2. Mueller, M.; Hobiger, S.; Jungbauer, A. Anti-inflammatory activity of extracts from fruits, herbs and spices. Food Chem. 2010, 122, 987-996. [CrossRef]

3. Marletta, M.A. Nitric oxide synthase structure and mechanism. J. Biol. Chem. 1993, 268, 12231-12234. [PubMed]

4. Nathan, C.; Xie, Q.W. Regulation of biosynthesis of nitric oxide. J. Biol. Chem. 1994, 269, 13725-13728. [PubMed]

5. Cheeseman, K.H.; Albano, E.F.; Thomasi, A.; Slater, T. Biochemical studies on the metabolic activation of halogenated alkanes. Environ. Health Perspect. 1985, 64, 85-101. [CrossRef] [PubMed]

6. Nguyen, T.; Brunson, D.; Crepsi, C.L.; Penman, B.W.; Wishnok, J.S.; Tannenbaum, S.R. DNA damage and mutation in human cells exposed to nitric oxide in vitro. Proc. Natl. Acad. Sci. USA 1992, 89, 3030-3034. [CrossRef] [PubMed] 
7. Rogoveanu, O.C.; Streba, C.T.; Vere, C.C.; Petrescu, L.; Trăistaru, R. Superior digestive tract side effects after prolonged treatment with NSAIDs in patients with osteoarthritis. J. Med. Life 2015, 8, 458-461. [PubMed]

8. Sanford, H.R. Nonsteroidal anti-inflammatory drug gastropathy: New avenues for safety. Clin. Interv. Aging 2011, 6, 125-131.

9. Kang, H.S.; Ock, J.; Lee, H.J.; Lee, Y.J.; Kwon, B.M.; Hong, S.H. Early growth response protein 1 upregulation and nuclear translocation by 2'-benzoyloxycinnamaldehyde induces prostate cancer cell death. Cancer Lett. 2013, 329, 217-227. [CrossRef] [PubMed]

10. Vaish, V.; Piplani, H.; Rana, C.; Vaiphei, K.; Sanyal, S.N. NSAIDs may regulate EGR-1-mediated induction of reactive oxygen species and non-steroidal anti-inflammatory drug-induced gene (NAG)-1 to initiate intrinsic pathway of apoptosis for the chemoprevention of colorectal cancer. Mol. Cell. Biochem. 2013, 378, 47-64. [CrossRef] [PubMed]

11. Droge, W. Free radicals in the physiological control of cell function. Physiol. Rev. 2002, 82, 47-95. [CrossRef] [PubMed]

12. Maroon, J.C.; Bost, J.W.; Maroon, A. Natural anti-inflammatory agents for pain relief. Surg. Neurol. Int. 2010, 1-80. [CrossRef]

13. Topol, E.J. Failing the public health-Rofecoxib, Merck, and the FDA. N. Engl. J. Med. 2004, 351, 1707-1709. [CrossRef] [PubMed]

14. Ambati, R.R.; Phang, S.M.; Ravi, S. Astaxanthin: Extraction, stability, biological activities and its commercial applications-A review. Mar. Drugs 2014, 12, 128-152. [CrossRef] [PubMed]

15. Guerin, M.; Huntley, M.E.; Olaizola, M. Haematococcus astaxanthin: Applications for human health and nutrition. Trends Biotechnol. 2003, 21, 210-216. [CrossRef]

16. Naguib, Y.M.A. Antioxidant activities of astaxanthin and related carotenoids. J. Agric. Food Chem. 2000, 48, 1150-1154. [CrossRef] [PubMed]

17. Kim, J.H.; Chang, M.J.; Choi, H.D.; Youn, Y.K.; Kim, J.T.; Oh, J.M. Protective effects of Heamatococcus astaxanthinon oxidative stress in healthy smokers. J. Med. Food 2011, 14, 1469-1475. [CrossRef] [PubMed]

18. Rodrigues, E.; Mariutti, L.R.; Mercadante, A.Z. Scavenging capacity of marine carotenoids against reactive oxygen and nitrogen species in a membrane-mimicking system. Mar. Drugs 2012, 10, 1784-1798. [CrossRef] [PubMed]

19. Valko, M.; Leibfritz, D.; Moncol, J.; Cronin, M.T.; Mazur, M.; Telser, J. Free radicals and antioxidants in normal physiological functions and human disease. Int. J. Biochem. Cell Biol. 2007, 39, 44-84. [CrossRef] [PubMed]

20. Chew, B.P.; Park, J.S.; Wong, M.W.; Wong, T.S. A comparison of the anticancer activities of dietary beta-carotene, canthaxanthin and astaxanthin in mice in vivo. Anticancer Res. 1999, 19, 1849-1853. [PubMed]

21. Li, Z.; Wang, Y.; Mo, B. The effects of carotenoids on the proliferation of human breast cancer cell and gene expression of bcl-2. Zhonghua Yu Fang Yi Xue Za Zhi 2002, 36, 254-257. [PubMed]

22. Palozza, P.; Torelli, C.; Boninsegna, A.; Simone, R.; Catalano, A.; Mele, M.C.; Picci, N. Growth-inhibitory effects of the astaxanthin-rich alga Haematococcuspluvialis in human colon cancer cells. Cancer Lett. 2009, 283, 108-117. [CrossRef] [PubMed]

23. Choi, S.K.; Park, Y.S.; Choi, D.K.; Chang, H.I. Effects of astaxanthin on the production of NO and the expression of COX-2 and iNOS in LPS-stimulated BV2 microglial cells. J. Microbiol. Biotechnol. 2008, 18, 1990-1996. [PubMed]

24. Kishimoto, Y.; Tani, M.; Uto-Kondo, H.; Iizuka, M.; Saita, E.; Sone, H. Astaxanthin suppresses scavenger receptor expression and matrix metalloproteinase activity in macrophages. Eur. J. Nutr. 2010, 49, 119-126. [CrossRef] [PubMed]

25. Yasui, Y.; Hosokawa, M.; Mikami, N.; Miyashita, K.; Tanaka, T. Dietary astaxanthin inhibits colitis and colitis-associated colon carcinogenesis in mice via modulation of the inflammatory cytokines. Chem. Biol. Interact. 2011, 193, 79-87. [CrossRef] [PubMed]

26. Winter, C.A.; Risley, E.A.; Nuss, G.W. Carrageenan-induced edema in hind paw of the rat as an assay for anti-inflammatory drugs. Proc. Soc. Exp. Biol. Med. 1962, 111, 544-547. [CrossRef] [PubMed]

27. Boughton-Smith, N.K.; Deakin, A.M.; Follenfant, R.L.; Whittle, B.J.; Garland, L.G. Role of oxygen radicals and arachidonic acid metabolites in the reverse passive Arthus reaction and carrageenin paw oedema in the rat. Br. J. Pharmacol. 1993, 110, 896-902. [CrossRef] [PubMed] 
28. Di Rosa, M.; Giroud, J.P.; Willoughby, D.A. Studies on the mediators of the acute inflammatory response induced in rats in different sites by carrageenan and turpentine. J. Pathol. 1971, 104, 15-29. [CrossRef] [PubMed]

29. Vinegar, R.; Schreiber, W.; Hugo, R. Biphasic development of carrageenin edema in rats. J. Pharmacol. Exp. Ther. 1969, 166, 96-103. [PubMed]

30. Vinegar, R.; Truax, J.F.; Selph, J.L.; Johnston, P.R.; Venable, A.L.; McKenzie, K.K. Pathway to carrageenan-induced inflammation in the hind limb of the rat. Fed. Proc. 1987, 46, 118-126. [PubMed]

31. Busnardo, T.C.; Padoani, C.; Mora, T.C.; Biavatti, M.W.; Fröde, T.S.; Bürger, C.; Claudino, V.D.; Dalmarco, E.M.; de Souza, M.M. Anti-inflammatory evaluation of Coronopus didymus in the pleurisy and paw oedema models in mice. J. Ethnopharmacol. 2010, 128, 519-525. [CrossRef] [PubMed]

32. Nathan, C. Perspective series: Nitric oxide and nitric oxide synthesis. J. Clin. Investig. 1997, 100, $2417-2423$. [CrossRef] [PubMed]

33. Salvemini, D.; Wang, Z.Q.; Wyatt, P.S.; Bourdon, D.M.; Marino, M.H.; Manning, P.T.; Currie, M.G. Nitric oxide: A key mediator in the early and late phase of carrageenan-induced rat paw inflammation. Br. J. Pharmacol. 1996, 118, 829-838. [CrossRef] [PubMed]

34. Beloeil, H.; Asehnoune, K.; Moine, P.; Benhamou, D.; Mazoit, J.X. Bupivacaine's action on the carrageenan-induced inflammatory response in mice: Cytokine production by leukocytes after ex vivo stimulation. Anesth. Analg. 2005, 100, 1081-1086. [CrossRef] [PubMed]

35. Posadas, I.; Bucci, M.; Roviezzo, F.; Rossi, A.; Parente, L.; Sautebin, L.; Cirino, G. Carrageenan-induced mouse paw oedema is biphasic, age-weight dependent and displays differential nitric oxide cyclooxygenase-2 expression. Br. J. Pharmacol. 2004, 142, 331-338. [CrossRef] [PubMed]

36. Cunha, T.M.; Verri, W.A., Jr.; Silva, J.S.; Poole, S.; Cunha, F.Q.; Ferreira, S.H. A cascade of cytokines mediates mechanical inflammatory hypernociception in mice. Proc. Natl. Acad. Sci. USA 2005, 102, 1755-1760. [CrossRef] [PubMed]

37. Verri, W.A., Jr.; Cunha, T.M.; Parada, C.A.; Poole, S.; Cunha, F.Q.; Ferreira, S.H. Hypernociceptive role of cytokines and chemokines: Targets for analgesic drug development? Pharmacol. Ther. 2006, 112, 116-138. [CrossRef] [PubMed]

38. Verri, W.A., Jr.; Cunha, T.M.; Poole, S.; Ferreira, S.H.; Cunha, F.Q. Cytokine inhibitors and pain control. Rev. Bras. Reum. 2007, 47,341-353. [CrossRef]

39. Wang, Z.Q.; Porreca, F.; Cuzzocrea, S.; Galen, K.; Lightfoot, R.; Masini, E.; Muscoli, C.; Mollace, V.; Ndengele, M.; Ischiropoulos, H.; et al. A newly identified role for superoxide in inflammatory pain. J. Pharmacol. Exp. Ther. 2004, 309, 869-878. [CrossRef] [PubMed]

40. Jin, X.; Gereau, R.W. Acute p38-mediated modulation of tetrodotoxin-resistant sodium channels in mouse sensory neurons by tumor necrosis factor-alpha. J. Neurosci. 2006, 26, 246-255. [CrossRef] [PubMed]

41. Binshtok, A.M.; Wang, H.; Zimmermann, K.; Amaya, F.; Vardeh, D.; Brenner, G.J.; Shi, L.; Ji, R.R.; Bean, B.P.; Woolf, C.J.; et al. Nociceptors are interleukin-1beta sensors. J. Neurosci. 2008, 28, 14062-14073. [CrossRef] [PubMed]

42. Satoh, M.; Kuraishi, Y.; Kawamura, M. Effects of intrathecal antibodies to substance P, calcitonin-gene related peptide and galanin on repeated cold stress-induced hyperalgesia: Comparison with carrageenan-induced hyperalgesia. Pain 1992, 49, 273-278. [CrossRef]

43. Sammons, M.J.; Raval, P.; Davey, P.T.; Rogers, D.; Persons, A.A.; Bingham, S. Carrgeenan-induced thermal hyperalgesia in the mouse: Role of nerve growth factor and the mitogen-activated protein kinase pathway. Brain Res. 2000, 876, 48-54. [CrossRef]

44. Speranza, L.; Pesce, M.; Patruno, A.; Franceschelli, S.; Anna de Lutiis, M.; Grilli, A.; Felaco, M. Astaxanthin Treatment Reduced Oxidative Induced Pro-Inflammatory Cytokines Secretion in U937: SHP-1 as a Novel Biological Target. Mar. Drugs 2012, 10, 890-899. [CrossRef] [PubMed]

45. Schierwagen, C.; Bylund-Fellenius, A.C.; Lundberg, C. Improved method for quantification of tissue PMN accumulation measured by myeloperoxidase activity. J. Pharmacol. Meth. 1990, 23, 179-186. [CrossRef]

46. Mittal, M.; Siddiqui, M.R.; Tran, K.; Reddy, S.P.; Malik, A.B. Reactive oxygen species in inflammation and tissue injury. Antioxid Redox Signal. 2014, 20, 1126-1167. [CrossRef] [PubMed]

47. Geronikaki, A.A.; Gavalas, A.M. Antioxidants and inflammatory disease: Synthetic and natural antioxidants with anti-inflammatory activity. Comb. Chem. High Throughput Screen. 2006, 9, 425-442. [CrossRef] [PubMed] 
48. Dawson, J.; Sedgwick, A.D.; Edwards, J.C.; Lees, P. A comparative study of the cellular, exudative and histological responses to carrageenan, dextran and zymosan in the mouse. Int. J. Tissue React. 1991, 13, 171-185. [PubMed]

49. Janero, D.R. Malondialdehyde and thiobarbituric acid reactivity as diagnostic indices of lipid peroxidation and peroxidative tissue injury. Free Radic. Biol. Med. 1990, 9, 515-540. [CrossRef]

50. Flemming, N.; Mikkelsen, B.B.; Nielsen, J.B.; Andersen, H.R.; Grandjean, P. Plasma malondialdehyde as biomarker for oxidative stress: Reference interval and effects of life-style factors. Clin. Chem. 1997, 43, 1209-1214.

51. Dose, J.; Matsugo, S.; Yokokawa, H.; Koshida, Y.; Okaxaki, S.; Seidel, U.; Eggersdorfer, M.; Rimbach, G.; Esatbeyoglu, T. Free radical scavenging and cellular antioxidant properties of astaxanthin. Int. J. Mol. Sci. 2016, 17, 103. [CrossRef] [PubMed]

52. Salvemini, D.; Wang, Z.Q.; Bourdon, D.M.; Stern, M.K.; Currie, M.G.; Manning, P.T. Evidence of peroxynitrite involvement in the carrageenan-induced rat paw edema. Eur. J. Pharmacol. 1996, 303, 217-220. [CrossRef]

53. Oyanagui, Y. Inflammation and superoxide production by macrophages. Agents Actions Suppl. 1980, 7, 174-179. [PubMed]

54. Oyanagui, Y.; Sato, S.; Okajima, T. Suppressions of ischemic paw oedema in mice, rats and guinea pigs by superoxide dismutases from different sources. Free Radic. Res. Commun. 1988, 4, 385-396. [CrossRef] [PubMed]

55. Kurashiqe, M.; Okimasu, E.; Inoue, M.; Utsumi, K. Inhibition of oxidative injury of biological membranes by astaxanthin. Physiol. Chem. Phys. Med. NMR 1990, 22, 27-38.

56. Neto, A.G.; Costa, J.M.L.C.; Belati, C.C.; Vinholis, A.H.C.; Possebom, L.S.; da Silva Filho, A.A.; Cunha, W.R.; Carvalho, J.C.T.; Bastos, J.K.; Silva, M.L.A. Analgesic and anti-inflammatory activity of a crude root extract of Pfaffia glomerata (Spreng) Pedersen. J. Ethnopharmacol. 2005, 96, 87-91. [CrossRef] [PubMed]

57. Cerella, C.; Sobolewski, C.; Dicato, M.; Diederich, M. Targeting COX-2 expression by natural compounds: A promising alternative strategy to synthetic COX-2 inhibitors for cancer chemoprevention and therapy. Biochem. Pharmacol. 2010, 80, 1801-1815. [CrossRef] [PubMed]

58. Ong, C.K.S.; Lirk, P.; Tan, C.H.; Seymour, R.A. An evidence-based update on nonsteroidal anti-inflammatory drugs. Clin. Med. Res. 2007, 5, 19-34. [CrossRef] [PubMed]

59. Lo, V.; Meadows, S.E.; Saseen, J. When should COX-2 selective NSAIDs be used for osteoarthritis and rheumatoid arthritis? J. Fam. Pract. 2006, 55, 260-262. [PubMed]

60. Sindhu, S.; Sherief, P.M. Extraction, characterization, antioxidant and anti-inflammatory properties of Carotenoids from the shell waste of Arabian red shrimp Aristeus alcocki, Ramadan 19. Open Conf. Proc. J. 2011, 2, 95-103.

61. Kavitha, K.; Kowshik, J.; Kishore, T.K.K.; Baba, A.B.; Nagini, S. Astaxanthin inhibits NF-kB and Wnt/ $\beta$-catenin signaling pathways via inactivation of Erk/MAPK and PI3K/Akt to induce intrinsic apoptosis in a hamster model of oral cancer. Biochim. Biophys. Acta 2013, 1830, 4433-4444. [CrossRef] [PubMed]

62. Fassett, R.G.; Coombes, J.S. Astaxanthin: A potential therapeutic agent in cardiovascular disease. Mar. Drugs 2011, 9, 447-465. [CrossRef] [PubMed]

63. Yuan, J.P.; Peng, J.; Yin, K.; Wang, J.H. Potential health-promoting effects of astaxanthin: A high-value carotenoid mostly from microalgae. Mol. Nutr. Food Res. 2011, 55, 150-165. [CrossRef] [PubMed]

64. Yang, S.; Zhou, Q.; Yang, L.; Xue, Y.; Xu, J.; Xue, C. Effect of thermal processing on astaxanthin and astaxanthin esters in pacific white shrimp Litopenaeus vannamei. J. Oleo Sci. 2015, 64, 243-253. [CrossRef] [PubMed]

65. Miao, F.; Lu, D.; Li, Y.; Zeng, M. Characterization of astaxanthin esters in Heamatococcus pluvialis by Liquid Chromatography-Atmospheric Pressure Chemical Ionization Mass Spectrometry. Anal. Bio-Chem. 2006, 352, 176-181.

66. Zimmermann, M. Ethical guidelines for investigations of experimental pain in conscious animals. Pain 1983, 16, 109-110. [CrossRef]

67. Sachindra, N.M.; Bhaskar, N.; Mahendrakar, N.S. Carotenoids in crabs from marine and fresh waters of India. Lebensm. Wiss. Technol. 2005, 38, 221-225. [CrossRef]

68. Hargreaves, K.; Dubner, F.; Brown, C.; Flores, C.; Joris, J. A new and sensitive method for measuring thermal nociception in cutaneous hyperalgesia. Pain 1988, 32, 77-88. [CrossRef] 
69. Menendez, L.; Lastra, A.; Hidalgo, A.; Baamonde, A. Unilateral hot plate test: A simple and sensitive method for detecting central and peripheral hyperalgesia in mice. J. Neurosci. Meth. 2002, 113, 91-97. [CrossRef]

70. Nogueira, E.S.; Castro, E.R.; Mancuso, R.; Navarro, X. Randall-Selitto test: A new approach for the detection of neuropathic pain after spinal cord injury. J. Neurotrauma 2012, 29, 898-904. [CrossRef] [PubMed]

71. Toda, S.; Kumura, M.; Ohnishi, M. Effects of phenolcarboxylic acids on superoxide anion and lipid peroxidation induced by superoxide anion. Planta Med. 1991, 57, 8-10. [CrossRef] [PubMed]

72. Uchiyama, M.; Mihara, M. Determination of malonaldehyde precursor in tissue by thiobarbituric acid test. Anal. Biochem. 1978, 86, 271-278. [CrossRef]

73. Conti, S.; Costa, B.; Colleoni, M.; Parolaro, D.; Giagnoni, G. Antiinflammatory action of endocannabinoid palmitoylethanolamide and the synthetic cannabinoid nabilone in a model of acute inflammation in the rat. Br. J. Pharmacol. 2002, 135, 181-187. [CrossRef] [PubMed]

74. El Shenawy, S.M.; Abdel-Salam, O.M.; Baiuomy, A.R.; El Batran, S.; Arbid, M.S. Studies on the anti-inflammatory and anti-nociceptive effects of melatonin in the rat. Pharmacol. Res. 2002, 46, 235-243. [CrossRef]

Sample Availability: Not Available.

(C) 2016 by the authors; licensee MDPI, Basel, Switzerland. This article is an open access article distributed under the terms and conditions of the Creative Commons by Attribution (CC-BY) license (http://creativecommons.org/licenses/by/4.0/). 